\title{
A retrospective analysis of cervical smears for detection of precancerous lesions
}

\author{
Jha $\mathrm{A}^{1}$, Chaurasia $\mathrm{AK}^{2}$ \\ ${ }^{1}$ Department of Pathology, Maharajgunj Medical Campus, Institute of Medicine, Maharajgunj, Kathmandu, Nepal. \\ ${ }^{2}$ Department of Pathology, National Medical College, Birgunj, Nepal
}

\author{
Keywords: \\ LSIL; \\ HSIL; \\ AGC; \\ Pap; \\ Trichomonas; \\ Human Papilloma Virus.
}

\begin{abstract}
Background: Diseases of the cervix are common in women. Detection of neoplastic lesions is of prime importance in the evaluation of cervical smears although their frequency is less than the non-neoplastic conditions. Reactive and inflammatory conditions, however, may mimic or obscure the dysplastic changes. The aim of this study was to evaluate the frequencies of various inflammatory, reactive and neoplastic lesions in the cervical smears.
\end{abstract}

Materials and Methods: This was a retrospective study of 150 cases of cervical smears collected from medical record section of the hospital and Department of Pathology at National Medical College from April 2013 to April 2015.

Results: Of 150 patients who underwent cervical cytology, only 15 cases (10\%) had epithelial cell abnormalities. This was followed by reactive cellular changes associated with inflammation (16.7\%), infections $(5.3 \%)$ and atrophy $(1.3 \%)$. Low grade squamous intraepithelial lesion $(6 \%)$ was the most common epithelial cell abnormality followed by high grade squamous intraepithelial lesion (2\%), atypical glandular cells (1.3\%) and squamous cell carcinoma (0.7\%).

Conclusion: Reactive changes including atrophy were the commonest finding. Squamous intraepithelial lesion was commonest finding among epithelial abnormalities. Glandular intraepithelial lesions and squamous cell carcinoma were also identified. Among infections Trichomoniasis and candidiasis were seen.

\section{INTRODUCTION}

Cervical cancer is the second most common cancer in women following breast cancer. ${ }^{1}$ The incidence of cervical cancer has dropped rapidly after introduction of cervical smear screening program. ${ }^{2}$ Squamous intraepithelial lesions

\section{Correspondence:}

Dr Abhimanyu Jha, MBBS, MD

Associate Professor, Department of Pathology

Maharajgunj Medical Campus, TU, IOM, Kathmandu, Nepal

Email: jhaabhimanyu@yahoo.com. are precancerous and identification of which is the focus of cervical screening.

Neoplastic lesions are less frequently seen in cervical smears compared to non-neoplastic lesions. Low grade squamous intraepithelial lesion (LSIL), high grade squamous intraepithelial lesion (HSIL) and atypical glandular cells (AGC) and carcinoma are the common neoplastic lesions. 
Viruses especially high risk strains of Human papilloma virus (HPV) and Herpes simplex virus-2 (HSV-2) are implicated in the carcinogenesis of cervical intraepithelial neoplasia and cervical cancer. ${ }^{3-5}$ Intraepithelial neoplasia is a very critical point in the natural history of cervical carcinoma. In present study we evaluated cervical smear findings to detect frequency of various inflammatory, reactive and neoplastic lesions.

\section{MATERIALS AND METHODS}

This was a retrospective study of 150 cases of cervical smears. Prior to the study permission was obtained from institutional review committee. The data was obtained from the medical record section and Department of Pathology at National Medical College, Birgunj, Nepal from April 2013 to April 2015. The 2001 Bethesda system was used to categorize the smears. The findings were tabulated and analyzed in Microsoft Excel vesion 2007.

\section{RESULTS}

Out of 150 cases 100 cases did not reveal any significant pathology. Age range was 20 to 60 years. Epithelial cell abnormalities were detected in 25-60 yrs of age. Epithelial cell abnormalities were detected in only 15 cases $(10 \%)$ while eight cases had specific infections (table 1). Among epithelial cell abnormalities LSIL was the commonest findings (60\%) followed by HSIL, AGC and squamous cell carcinoma (table 2).

\section{DISCUSSION}

Cervical cancer is one of the leading causes of mortality and morbidity among women throughout the world. In developing countries it is the most common gynecological cancer and one of the leading causes of cancer death among women. Nearly four lacs new cases of cervical cancers are diagnosed annually worldwide and $80 \%$ of them are diagnosed in the developing countries. ${ }^{6}$ There should be an effective mass screening program aimed at specific age group for detecting precancerous condition before they progress to invasive cancers. ${ }^{7}$ Detection of epithelial cell abnormality as per guidelines of Bethesda system is

Table1: Frequency of various lesions in cervical smears

\begin{tabular}{lcc}
\hline Cervical cytology findings & No. of cases & Percentage \\
\hline Negative for intraepithelial lesions & 100 & $(66.66 \%)$ \\
$\begin{array}{l}\text { Reactive cellular changes associated with } \\
\text { inflammation }\end{array}$ & 25 & $(16.66 \%)$ \\
\hline Bacterial vaginosis & 5 & $(03.33 \%)$ \\
Candidiasis & 3 & $(01.33 \%)$ \\
\hline Atrophic Smear & 2 & $(01.30 \%)$ \\
\hline Epithelial cell abnormalities & 15 & $(10.00 \%)$ \\
Total & $\mathbf{1 5 0}$ & $\mathbf{1 0 0 \%}$
\end{tabular}

Table 2: Frequency of epithelial cell abnormalities

\begin{tabular}{lcc}
\hline Epithelial cell abnormalities & No. of cases & Percentage \\
\hline LSIL & 09 & $(60.00 \%)$ \\
\hline HSIL & 03 & $(20.00 \%)$ \\
\hline AGC & 02 & $(13.30 \%)$ \\
SCC & 01 & $(06.60 \%)$ \\
Total & 15 & $(100 \%)$
\end{tabular}

mainstay in the detection of precancerous lesion in cervical smears. ${ }^{8}$

In present study $10 \%$ of the cervical smears showed epithelial cell abnormalities. Mean age for epithelial cell abnormality was 40 year. Mean age was almost similar for LSIL and HSIL. Mean age of patients was $51.02 \pm 10.18$ years in the study of Ranabhat et al. ${ }^{9}$ Mean age of the patients with diagnosis of LSIL was 32.3 years and for HSIL it was 40.5 years in the study of Bal et al. ${ }^{10}$

In the study by Banik et al involving 1699 patients, the epithelial cell abnormality was seen in $8.18 \%$ cases. ${ }^{11}$ In the study of Bal et al and Ahmed et al, it was seen in 5\% and $1.3 \%$ respectively, and the former study involved only 300 cervical smears and later involved 7772 cases. ${ }^{11,12}$ In this study the frequency of epithelial cell abnormality is high as compared to other studies which can be as a result of less number of cases involved in the study.

Among epithelial cell abnormalities most common finding was LSIL that was followed by HSIL, AGC and SCC. In the study of Banik et al $(n=1699)$ LSIL was detected in $6.36 \%$ of cases, HSIL in $1.18 \%$ cases, AGC in $0.12 \%$ cases and malignancy in $0.35 \%$ of total cases. ${ }^{11}$ Considering the total cases in present study LSIL, HSIL, AGC and SCC were $0.06 \%, 0.02 \%, 0.01 \%$ and $0.006 \%$ respectively (table 2 ), while in the study by Ahmed et al $(\mathrm{n}=7772)$ these findings were, LSIL $(0.19 \%)$, HSIL $(0.37 \%)$, AGC $(0.25 \%)$, and SCC $(0.10 \%)$ respectively. ${ }^{12}$ Contrary to above studies in the study of Ranabhat et al HSIL was the commonest finding among epithelial cell abnormality. ${ }^{9}$ In present study specific infections were detected only in eight cases. In five cases it was bacterial vaginosis and in three cases it was candidiasis. In the study of Ranabhat et al Candidiasis, Trichomonisis, bacterial vaginosis and Herpes simplex infections were detected in nine cases (1\%), four cases $(0.45 \%), 67$ cases $(7.6 \%)$ and in three cases $(0.34 \%)$ respectively unlike present study.9 In the study Shurbaji et al Candida was identified in $309(3.0 \%)$ of the 10,370 smears. Ninety-nine (72\%) patients were asymptomatic, $29(21 \%)$ had symptoms typical of candidasis, and nine (7\%) had nonspecific symptoms. ${ }^{13}$ In present study although the number of cases was not comparable to the study of Shurbati et al, however, the percentage of detection of candida in cervical smears was similar and patient was asymptomatic. 


\section{CONCLUSION}

Conventional cervical smear screening remains the effective method of detection of precancerous lesions of cervix. Detection of either squamous or glandular intraepithelial lesions remains mainstay in the prevention of cervical cancer. This test also contributes in detection of various infectious agents that may associated with significant morbidity and cervical carcinogenesis.

\section{REFERENCES}

1. Elkas J, Faries-Einser R. Cancer of the uterine cervix. Curr Opin Obstet Gynaecol 1998;10:47-50. Crossref

2. Landis SH, Murray T, Bolden S. Cancer Statistics, 1998. CA Cancer J Clin 1998;48: 6-29. Crossref

3. Eileen M. Burd. Human Papillomavirus and Cervical Cancer. Clin Microbiol Rev. 2003;16:1-17. Crossref

4. Jones C. Cervical cancer: is herpes simplex virus type II a cofactor? Clin Microbiol Rev. 1995;8:549-56.

5. Koffa M, Koumantakis E, Ergazaki M, Tsatsanis C, Demetrios A. Spandidos. Association of herpesvirus infection with the development of genital cancer. Int J Cancer 1995;63:58-62. Crossref

6. Patel MM, Pandya AN, Modi J. Cervical PAP smear study and its utility in cancer screening, to specify the strategy for cervical cancer control. National Journal of Community Medicine 2011;2:49-51.
7. Khan MS, Raja FY, Ishfaq G, Tahir F, Subhan F, Kazi BM et al. PAP smear screening for pre-cancerous conditions of the cervical cancers. Pak J Med Res 2005;44:111-3.

8. Massad LS, Einstein MH, Huh WK et al. 2012 Updated Consensus Guidelines for the Management of Abnormal Cervical Cancer Screening Tests and Cancer Precursors. American Society for Colposcopy and Cervical Pathology. Journal of Lower Genital Tract Disease 2013;17:S1-S27. Crossref

9. Ranabhat SK, Shrestha R, Tiwari M. Analysis of abnormal epithelial lesions in cervical Pap smears in Mid-Western Nepal. Journal of Pathology of Nepal 2011;1:30-3. Crossref

10. Bal MS, Goyal R, Suri AK, Mohi MK. Detection of abnormal cervical cytology in Papanicolaou smears.J Cytol. 2012;29:45-7. Crossref

11. Banik U, Bhattacharjee P, Ahamad SU, Rahman Z. Pattern of epithelial cell abnormality in Pap smear: A clinicopathological and demographic correlation. Cytojournal. 2011;8:8. Crossref

12. Ahmed A. Spectrum of cervical epithelial cell abnormalities diagnosed at King Fahd Hospital of the University Al-Khobar Saudi Arabia. Gomal J Med Sci 2012;10:172-7.

13. Shurbaji MS, Burja IT, Sawyer WL Jr. Clinical significance of identifying candida on cervicovaginal (Pap) smears. Diagn Cytopathol. 1999;21:14-7. Crossref 